\title{
Study on Thévenin Equivalent Circuit Modeling of Zinc-Nickel Single-Flow Battery
}

\author{
Shouguang Yao ${ }^{1, *}$, PengLiao $^{1}$, Min Xiao $^{1}$, Jie Cheng ${ }^{2}$, Liang Xu ${ }^{2}$ \\ ${ }^{1}$ Jiangsu University of Science and Technology, Zhenjiang, 212003, China \\ ${ }^{2}$ Zhangjiagang Smartgrid Fanghua Electrical Energy Storage Research Institute Co., Ltd, \\ Zhangjiagang, 215600, China \\ *E-mail: zjyaosg@126.com
}

doi: $10.20964 / 2018.05 .63$

Received: 17 January 2017 / Accepted: 13 March 2018 / Published: 10 April 2017

\begin{abstract}
Based on the working principle of a zinc-nickel single-flow battery (ZNB), an improved Thévenin equivalent circuit model is proposed in this paper. According to the experimental data of a 100-A pulsed discharge of a ZNB, the parameters of the modified model were obtained based on the parameter identification principle and the least squares curve fitting method first, then the discrete mathematical models of the model voltages were built in a MATLAB/Simulink environment. The simulation results show that the stack voltage's maximum relative error for the Thévenin model is $5.2 \%$ when compared with the experimental results under a 100-A constant-current discharge; the corresponding value of the improved model is $2.38 \%$, and the relative error of the improved model is lower than that of the Thévenin model over the entire discharge process, which indicates that the improved model has higher accuracy and a more accurate prediction of the stack voltage for the battery constant-current discharge.
\end{abstract}

Keywords: zinc-nickel single-flow battery; Thévenin model; discrete mathematical model; parameter identification; model simulation

\section{FULL TEXT}

(C) 2018 The Authors. Published by ESG (www.electrochemsci.org). This article is an open access article distributed under the terms and conditions of the Creative Commons Attribution license (http://creativecommons.org/licenses/by/4.0/). 